Japanese Psychological Research

1984, Vol. 26, No. 4, 187-193

\title{
The effect of discussion on polarization of judgments
}

\author{
MIKITOSHI ISOZAKI ${ }^{1}$ \\ Department of Psychology, Faculty of Education, Aichi University of Education, Kariya, Aichi 448
}

\begin{abstract}
The present study was conducted to examine the effects of discussion on group decisions and individual judgments, and to verify the tendency of group polarization through discussion. In Experiment I, 4- or 5-person groups responded three times to two jury cases (Case 1: a traffic case, Case 2: an euthanasia problem) in the order of individual-group-individual. The results showed that group polarization did not occur in Case 1, and depolarization tended to occur in Case 2. Group members seemed not enough share their initial judgments in these cases. In Experiment II, 4- or 5-person groups responded three times to a traffic case in which the defendant obviously appeared guilty. The order of responding was individual-groupindividual. The results showed that not only group polarization but also confidence in the judgment significantly increased following discussion. The subjects also declared themselves more satisfied with the result of discussion in Experiment II than in Experiment I. The results were discussed in terms of both informational influence and social comparison.
\end{abstract}

Key words: group polarization, group influence, group decision, informational influence, social comparison.

The purpose of this study is to examine the effects of discussion on group decisions and individual judgments, and to verify the tendency of group polarization. Group polarization refers to the fact that " the average postgroup response will tend to be more extreme in the same direction as the average of the pregroup response" (Myers \& Lamm, 1976). Risky-shift phenomenon discovered on "Choice Dilemma" items is now widely described as a group polarization (Myers \& Lamm, 1975, 1976).

In an earlier study Moscovici and Zavalloni (1969) found that French students initially favorable to General de Gaulle intensified their attitudes after their discussion, but on the other hand the subjects initially unfavorable to Americans intensified their negative attitudes after the discussion. Similarly, several experiments suggest that group members tend to become more extreme in their views following discussion (e.g., Myers \& Bishop, 1970).

1 The author is grateful to Mr. Isao Takahashi and Mr. Kazuhisa Isozaki for helpful suggestions concerning English expression.
In the experiment of Myers and Bach (1974), however, group-polarization hypothesis was not confirmed. Myers and Bach composed groups of relatively pacifistic subjects (doves) and groups of relatively militalistic subjects (hawks). Contrary to prediction, both communities of subjects shifted to increased pacifism following discussion. According to Myers and Bach, this finding suggests a caution in extending the group-polarization hypothesis to situations involving separation and grouping on the basis of initial attitudes. The result that hawks shifted to increased pacifism following discussion seems due to restraint by their perception of a social norm. Therefore, it is necessary to examine further the evidence relating to the occurrence of polarization effect, and to account for the conditions under which and the reasons why group polarization occurs.

There are two theoretical explanations on group polarization, informational influence (e.g., Burnstein \& Vinokur, 1975) and social comparison (e.g., Goethals \& Zanna, 1979; Jellison \& Riskind, 1970). According to Myers (1982), "the infor- 
mational influence explanation stresses our rational capacities-persuasive discussion arguments are presumed to predominantly favor the initially preferred alternative, thereby enhancing it. Social comparison explanations stress social motivation-people presumably want to perceive and present themselves favorably, so exposure to others' positions may stimulate them to adjust their responses in order to maintain a desirable image" (Myers, 1982, p. 140). Social comparison explanation assumes that individuals often tend to perceive themselves as being more extreme than others in the "right" direction, and they modify their responses when they discover that others share the individuals' inclinations more than they would have supposed (e.g., Jellison \& Arkin, 1977). Using choice-dilemma items, McCauley, Kogan, and Teger (1971), Wallach and Wing (1968) found that consistent with social comparison assumption, subjects tended to perceive their peers as less risky than themselves. And Myers and Bishop (1971) confirmed the tendency to see others as more neutral than themselves on nonrisk materials. Another concern of the present study is to examine social comparison theory's assumption that individuals tend to see themselves as being more extreme than others in the "right" directions.

As to group discussion, Zaleska (1982) points out that discussions between strangers result more often in compromise solutions than discussions between friends since it may be expected that a friendly and accepting climate will facilitate even the expression of very extreme opinions or attitudes. In a friendly and accepting climate there should be less fear of rejection but more involvement in the discussion. It seems that affective factors are closely related to discussion and group decision. Therefore, the present study was conducted in groups of four or five persons who knew each other.

\section{Experiment I}

The purpose of this experiment is to investigate the effect of discussion on polarization of judgments by using jury cases. Another concern of the present experiment is to examine social comparison theory's assumption that individuals tend to see themselves as being more extreme than others in the "right" direction.

\section{Method}

Subjects. The subjects were 38 university students, 14 men and 24 women. The subjects participated in same-sex groups of four or five. Each group was composed of subjects who knew each other.

Materials. The materials used in the present experiment were two jury cases. One was a traffic case: an old man was run over by a car on a pedestrian crossing while the pedestrian lights showed "stop" (The defendant was the driver of the car: Case 1). The other was an euthanasia problem: a man killed his son for his euthanasia (Case 2). These cases were prepared referring to the ones in Mishima (1977).

Procedure. The experiment was conducted in groups of four or five persons. Each group member was seated at a desk partitioned by screens each other (Communication Net-II, Takei Co.). The subjects were given a booklet containing two cases and related questions. The experimenter began by instructing subjects to judge each case as if they were judges, and to respond individually to the following questions on a 11-point (0-10) scale (initial judgment).

1. degree of guilt

(0) definitely not guilty-(10) definitely guilty

2. estimates of average student's judgment

(0) definitely not guilty-(10) definitely guilty

3. degree of confidence in one's own judg- 
ment on degree of guilt

(0) not confident at all-(10) extremely confident

4. degree of interest in the case

(0) not interesting at all-(10) extremely interesting

After the subjects responded to these questions on each case, the booklets were collected. Then they were asked to discuss each case in turn about 5 to 10 minutes and to reach a unanimous decision both on degree of guilt and on estimates of average student's judgment (group consensus). One of group members signaled the experimenter the end of discussion and the experimenter measured the duration of discussion in each case. After the group discussion, the subjects were again asked to judge each case and to respond to the following questions on each individually (final judgment).

1. degree of guilt

(0) definitely not guilty-(10) definitely guilty

2. degree of confidence in one's own judgment on degree of guilt

(0) not confident at all-(10) extremely confident

3. degree of satisfaction with the discussion result

(0) not satisfactory at all-(10) extremely satisfactory

4. rating of the progress of group discussion

(0) not good at all-(10) extremely good

\section{Results and Discussion}

The mean ratings of interest in each case was nearly equal (Case 1: $M=7.53$, $S D=1.90 ;$ Case $2: M=7.50, S D=2.00$ ). The mean ratings of degree of guilt and the mean estimates of average student's judgment in Case 1 are shown in Fig. 1. The results in Case 2 are shown in Fig. 2. In Case 1, the number of harsh (above middle scalc value) and lenient (middle scale value and below) groups was 3 and 5 , respectively. In Case 2, the number of harsh and lenient groups was 1 and 7, respectively.

With respect to the ratings of degree of guilt, the predicted polarization did not occur in Case 1. In Case 2, depolarization tended to occur in lenient groups fol-

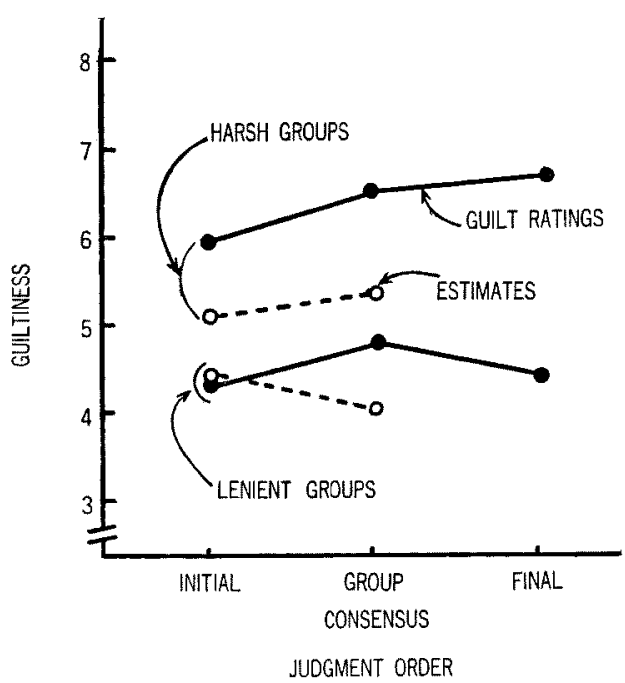

Fig. 1. Mean ratings of the degree of guilt, and mean estimates of average student's judgment (Case 1).

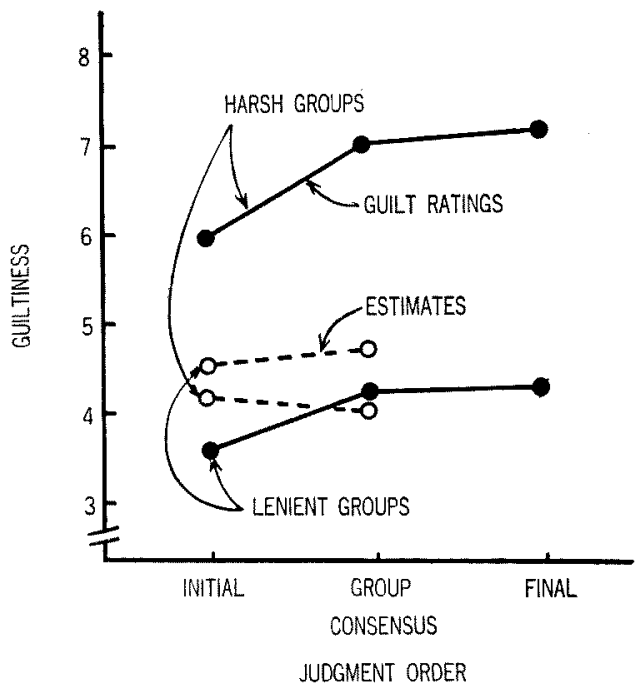

Fig. 2. Mean ratings of the degree of guilt, and mean estimates of average student's judgment (Case 2). 
lowing discussion. The difference between the initial and the final mean ratings of degree of guilt was not enough significant $(t=1.99, d f=32, p<.10)$. The results in Case 2 may be partly attributed to the pre-existing external value, e.g., the dignity of life. The results, in a sense, may correspond with those of the previous study by Myers and Bach (1974).

There was a significant difference between the initial mean ratings of degree of guilt and the mean estimates of average student's judgment in harsh groups in Case l $(t=2.74, d f=14, p<.05)$. Similarly, there was a difference of the same kind in lenient groups in Case 2 though not enough significant statistically $(t=1.95, d f=32, p$ $<.10)$. These differences may coincide with the social comparison theory's assumption that we often tend to perceive ourselves as being more extreme in the "right" direction. But the results of mean ratings of degree of guilt following discussion seemed not sufficiently consistent with social comparison theory's assumptions. As to the mean ratings of confidence in one's own judgment on degree of guilt, no significant difference was found between the initial and the final ratings in Case 1 nor in Case 2.

In the present experiment, subjects responded to the cases in which the defendants did not obviously appear guilty nor innocent. Consequently the group members did not enough share their initial judgments. In choice-dilemma items used in previous studies by Jellison and Riskind (1970, 1971), the extremity of judgment tends to correspond to ability levels and values members perceive. Therefore, in Experiment II, the effect of discussion on polarization of judgments was tested by using a case which elicits a predominant predisposition. Under such conditions, group members will share their initial judgments and polarizing effect of discussion will become more salient.

\section{Experiment II}

The present experiment was conducted to investigate again the effect of discussion on polarization of judgments, and also to examine social comparison theory's assumption by using a jury case contrived to give a predominantly higher appearance of guilt.

\section{Method}

Subjects. The subjects were 35 university students, 14 men and 21 women. The subjects participated in same-sex groups of four or five. Each group was composed of subjects who knew each other.

Materials. The material was the same as Case 1 used in Experiment I except that the driver was drunk, i.e., "Mr. A was tired, because he had worked late. After he drank beer, he was driving the car home. The car was nearing his home and the traffic signal was green. All of a sudden, he found an old man crossing the road at the pedestrian crossing. Though he turned the wheel at once and put on the brakes, his car run over the old man. $\mathrm{He}$ got too confused to calm down his feelings. He didn't know if he should blame the old man for ignoring the signal or blame himself for driving drunk and not slowing down the car." This case was contrived to give a predominantly high appearance of guilt.

Procedure. The procedure in the present experiment was almost identical to the one used in Experiment I. The experiment was conducted in groups of four or five persons. The subjects were given a booklet containing the traffic case and related questions. The experimenter instructed the subjects to judge degree of guilt of the defendant and to answer some other questions individually (initial judgment). These questions were identical to the ones used in Experiment I. After that, the subjects were requested to discuss the case and to reach a unanimous decision both on degree of guilt and on estimates 
of average student's judgment in the case (group consensus). The experimenter measured the duration of discussion. After the group discussion, the subjects were again asked to judge the case and to answer some other questions individually (final judgment). The questions were also identical to the ones used in Experiment I.

\section{Resulls and Discussion}

The mean ratings of interest in the case was $7.83(S D=2.22)$. The mean ratings of degree of guilt and the mean estimates of average student's judgment in the case are shown in Fig. 3. All the subject groups (eight groups) were harsh in the initial mean ratings of degree of guilt (above middle scale value).

A single-factor analysis of variance with repeated measures on the same elements was employed to analyze the data (Winer, 1971, pp. 261-269). With respect to the ratings of degree of guilt, there was a significant main effect for judgment period $(F=5.81, d f=2 / 14, p<.05)$, showing that polarizing effect of group discussion occurred. The Newman-Keuls test showed

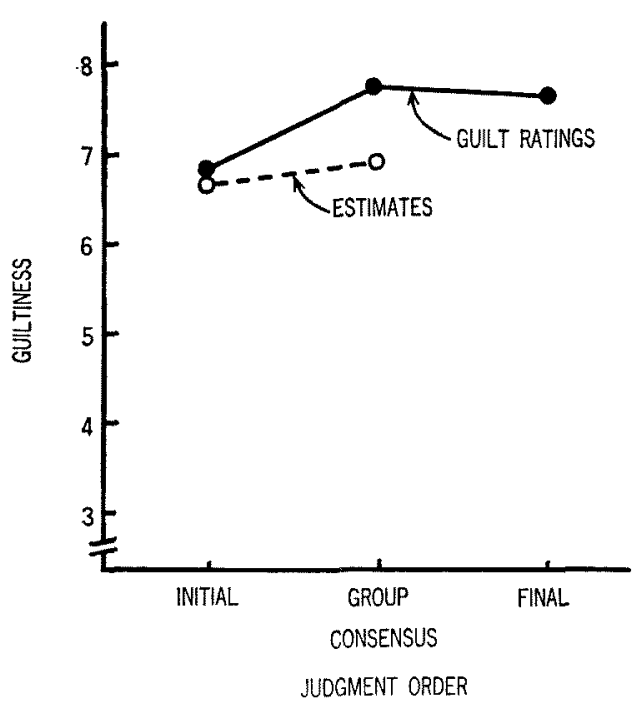

Fig. 3. Mean ratings of the degree of guilt, and mean estimates of average student's judgment (Experiment II). significant differences between the initial mean ratings and the mean ratings of "group consensus" ( $p<.05)$, and between the initial and the final mean ratings of degree of guilt $(p<.05)$. As predicted, the subjects initially harsh to the driver made harsher judgments of guilt following discussion.

There was not a significant difference between the initial mean ratings of degree of guilt and the initial mean estimates of average student's judgment. This result is not consistent with Jellison and Riskind's (1970) study with choice-dilemma items based on social comparison theory. But there was a slight though not enough significant difference between the mean guilt ratings and the mean judgment estimates of "group consensus" $(t=2.18$, $d f=7, p<.10)$. The guilt ratings seemed to be harsher than the judgment estimates. It is often pointed out that group members tend to perceive and present their own groups favorably, and to underestimate other groups. Tajfel and Forgas (1981) argues that social comparison processes play a very important role in betweengroup discrimination and in the creation and maintenance of positive social identities. In this way, the tendency to distinguish one's own group decision from other average student's judgment in the present experiment may suggest intergroup rather than interpersonal comparison.

The comparison of the initial mean ratings of confidence $(M=6.80, S D=1.79)$ to the final mean ratings of confidence $(M=$ $7.89, S D=1.37$ ) showed a significant difference $(t=5.62, d f=34, p<.001)$. Therefore, it was found that not only group polarization occurred but also the degree of confidence in one's own judgment increased following discussion. This means that the group members shift their judgments, to a certain extent, internally, and not superficially. Although not significant statistically, a correlation between the initial and the final ratings of degree of guilt was also in the direction predicted 
by informational influence theory $(r=$ -.21). According to informational influence theory, a group that is already quite extreme before discussion will not show as much polarization as a less extreme group. For the initially extreme group already shares the most persuasive arguments, whereas the less extreme group shares only partial arguments, and has to learn from exchanging arguments (see Myers, 1982). The results of Experiment II seem to give, at least to a certain degree, support to an explanation of group polarization in terms of informational influence theory. But as is shown in the difference between the mean guilt ratings and the mean judgment estimates of "group consensus", social comparison mechanism also seems partly to contribute to the group polarization.

Between the duration of discussion and the degree of polarization, there was no significant correlation $(r=-.17)$.

We should now note cognitive and affective factors in group discussion. In their responses to a post-experimental questionnaire, the subjects in Experiment II declared themselves more satisfied with the result of discussion than the subjects in Experiment I (Experiment II, $M=8.66, S D=$ 1.24; Case 1 in Experiment I, $M=7.42$, $S D=1.62: t=3.60, d f=71, p<.001)$. Similarly, the subjects in Experiment II rated the progress of the discussion more positively than the subjects in Experiment I (Experiment II, $M=8.34, S D=1.39$; Case 1 in Experiment I, $M=6.92, S D=1.81: \imath=3.68$, $d f=71, p<.001)$. These results seem to suggest that the relationship between group decision and group members' cognitive and affective factors. Further experiments should be done on this mediating role of cognitive and affective factors in group discussion. It also seems necessary to examine the content and process of discussion.

\section{References}

Burnstein, E., \& Vinokur, A. 1975 What a person thinks upon learning he has chosen differently from others: Nice evidence for the persuasive-arguments explanation of choice shifts. Journal of Experimental Social Psychology, 11, 412426.

Goethals, G. R., \& Zanna, M. P. 1979 The role of social comparison in choice shifts. Journal of Personality and Social Psychology, 37, 14691476.

Jellison, J. M., \& Arkin, R. M. 1977 Social comparison of abilities: A self-presentational approach to decision making in groups. In J. M. Suls \& R. L. Miller (Eds.), Social comparison processes. New York: Halsted Press. Pp. 235-257.

Jellison, J. M., \& Riskind, J. 1970 A social comparison of abilities interpretation of risktaking behavior. Journal of Personality and Social Psychology, 15, 375-390.

Jellison, J.M., \& Riskind, J. 1971 Attribution of risk to others as a function of their ability. Journal of Personality and Social Psychology, 20, 413415.

McGauley, C., Kogan, N., \& Teger, A. I. 1971 Order effects in answering risk dilemmas for self and others. Journal of Personality and Social Psychology, 20, 423-424.

Mishima, K. 1977 An experimental study of density effects on social interaction. Unpublished Master's thesis, Hiroshima University. (In Japanese)

Moscovici, S., \& Zavalloni, M. 1969 The group as a polarizer of attitudes. Journal of Personality and Social Psychology, 12, 125-135.

Myers, D. G. 1982 Polarizing effects of social interaction. In H. Brandstätter, J. H. Davis, \& G. Stocker-Kreichgaucr (Eds.), Group decision making. New York: Academic Press. Pp. 125161.

Myers, D. G., \& Bach, P.J. 1974 Discussion effects on militarism-pacifism: A test of the group polarization hypothesis. Journal of Personality and Social Psychology, 30, 741-747.

Myers, D. G., \& Bishop, G. D. 1970 Discussion effects on racial attitudes. Science, 169, 778-779.

Myers, D. G., \& Bishop, G. D. 1971 Enhancement of dominant attitudes in group discussion. Journal of Personality and Social Psychology, 20, 386-391.

Myers, D. G., \& Lamm, H. 1975 The polarizing effect of group discussion. American Scientist, 63, 297-303. 
Myers, D. G., \& Lamm, H. 1976 The group polarization phenomenon. Psychological Bulletin, 83, 602-627.

Tajfel, H., \& Forgas, J. P. 1981 Social categorization: Cognitions, values and groups. In J. P. Forgas (Ed.), Social cognition: Perspectives on everyday understanding. London: Academic Press. Pp. 113-140.

Wallach, M.A., \& Wing, C. W. Jr. 1968 Is risk a value? Journat of Personality and Social
Psychology, 9, 101-106.

Winer, B. J. 1971 Statislical principles in experimental design. 2nd ed. New York: McGrawHill,

Zaleska, M. 1982 Affective and motivational components of group induced opinion or attitude change. In H. Hiebsch (Ed.), Social psychology. Amsterdam: North-Holland. Pp. 107-113.

(Received June 27, 1983; accepted July 14, 1984) 